\title{
Effect of Types of Weir on Discharge
}

\author{
L L Caroline ${ }^{1}$, Nasser R Afshar ${ }^{2}$ \\ Date Received: $17^{\text {th }}$ July 2014 \\ Date Published: $1^{\text {st }}$ October 2014
}

\begin{abstract}
The measurement of discharge is one of the main concerns in hydraulic engineering. The study of types of weir on discharge is important as the knowledge of the accurate measurement of discharges helps in understanding of the flow mechanism as well as designing the hydraulic structures for future. Structures such as rectangular weir, vee notch weir and crump weir are placed in a channel to measure the flow rate. By using Bernoulli's equation, weir equation are derived and used to determine the flow rate. The main objective is to determine the optimum discharge for different types of weirs. This discharge is important in designing the hydraulic structure. Overestimated discharge may cause failure to the structure and if the discharge is underestimated, it may not fulfill the design requirements. The studies are experimented from maximum flow to minimum flow by measuring head over the weir for different working sections; flat and slope of 1:2400 and different height of partially opened sluice gate of $4 \mathrm{~cm}$ and $6 \mathrm{~cm}$ for crump drowned condition. The result shows that the coefficient of discharge, $C_{d}$ decreases when the head of water above the crest increases; except for crump weir in which $C_{d}$ is independent of the head. Meanwhile, the velocities when slope is 1:2400 are higher as compared to flat.
\end{abstract}

Keywords: Discharge, Head, Open channel, Velocity, Weirs.

\section{INTRODUCTION}

$\mathrm{T}$ HE purpose of this study is to present an analysis on effect of types of weir on discharge. A weir is an obstruction in open channel in which water must flow over and is used indirectly to obtain flow rate based on the weir geometry and the head on the weir crest [1]. Once the upstream water level exceeds the crest height of the weir, the water will start flow over the weir. As the depth of water above the weir, $h_{1}$ increases, the discharge over the weir, $Q$ will also increases correspondingly. The ideal relationship between $h_{l}$ and $Q$ may readily derive for each weir shape based on the basis of the Bernoulli equation [2]. This discharge depends on many parameters such as viscosity, surface tension and geometry, thus, it is difficult to calculate the exact value of discharge. Surface tension results from intermolecular forces which attracts molecules to one another. At the surface, forces are less than those within the fluid and as a result there is net tension over the surface. In water, due to intermolecular hydrogen bonding, this force is very strong and is the basis of capillary and the reason for the formation of familiar drops, bubbles and meniscuses [3]. In most natural fluid flows, surface tension is very small compared to other forces and can be ignored in majority cases [4]. The reasons of using coefficient of discharge, $C_{d}$ is that the flow heads at both upstream and over the crest are not equal due vertical curvature of the streamlines; another reason is due to the assumption that the pressure distribution upstream weir is hydrostatic [5]. Using Bernoulli's equation, weir equation can be derived and used to determine the flow rate as shown in Table 1:

Table 1 Flow equations for different weirs

\begin{tabular}{|c|c|c|}
\hline Weir & Equation & Remarks \\
\hline Rectangular & $\bullet Q=C_{d} \frac{2}{3} b \sqrt{2 g} h_{1}{ }^{3 / 2}$ & Bernoulli \\
\hline Vee notch & $\bullet Q=\frac{8}{15} C_{d} \sqrt{2 g} \tan (\alpha / 2) h_{1}{ }^{5 / 2}$ & Bernoulli \\
\hline Crump (undrowned condition) & $\bullet Q=\left(\frac{2}{3}\right)^{3 / 2} C_{d} C_{v} b \sqrt{g} \mathrm{~h}_{1}{ }^{3 / 2}$ & Tecquipment Manual \\
\hline Crump (drowned condition) & $\bullet Q=\left(\frac{2}{3}\right)^{3 / 2} C_{d} C_{v f} b \sqrt{g} \mathrm{~h}_{1}{ }^{3 / 2}$ & Tecquipment Manual \\
\hline
\end{tabular}

1. Student, Department of Civil Engineering, Faculty of Engineering, Universiti Malaysia Sarawak, 94300 Kota Samarahan, Sarawak, Malaysia (e-mail: ro_ling89@yahoo.com).

2. Associate Professor, Department of Civil Engineering, Faculty of Engineering, Universiti Malaysia Sarawak, 94300 Kota Samarahan, Sarawak, Malaysia (082583295; fax: 082583410;: e-mail: anrostam@ feng.unimas.my) 


\section{UNIMAS e-Journal of Civil Engineering}

Where,

$Q=$ Discharge $\left(\mathrm{m}^{3} / \mathrm{s}\right)$

$C_{d}=$ Coefficient of discharge

$h_{1}=$ Depth of water above the weir (m)

$b=$ Width of weir $(\mathrm{m})$

$\alpha=$ Angle $\left({ }^{0}\right)$

$g=$ Acceleration due to gravity $\left(\mathrm{m}^{2} / \mathrm{s}\right)$

$C_{v}=$ Coefficient of velocity for modular flow

$C_{v f}=$ Coefficient of velocity for non-modular flow

\section{EXPERIMENTAL SET-UP}

The experimental studies were performed in an open channel which is set up in Universiti Malaysia Sarawak (UNIMAS) Civil Engineering Hydraulics Laboratory(Figure 1). The channel has a rectangular cross section of $0.30 \mathrm{~m} \times 0.40 \mathrm{~m}$ and flow length of $8.00 \mathrm{~m}$. The velocity is determined using the ARMField H33-2 Current Meter. The current meter is positioned right before the weirs to measure the velocity. The data readings from the current meter that shown in Hertz (Hz) are then converted into velocity unit using the appropriate velocity- $\mathrm{Hz}$ graph provided by the manufacturer. The depth of flow in the channel has been determined using a point gauge. In order to improve the accuracy of the flow depth, average readings from the point gauge has been obtained. The studies are experimented with discharge ranges from $0.0014 \mathrm{~m}^{3} / \mathrm{s}$ to $0.015 \mathrm{~m}^{3} / \mathrm{s}$ with two different working sections; flat and slope. For slope working section, the channel bed slope parameter is set to 1:2400 gradients. In the drowned condition for Crump weir, the partially opened sluice gates are set to different height which is $4 \mathrm{~cm}$ and $6 \mathrm{~cm}$.

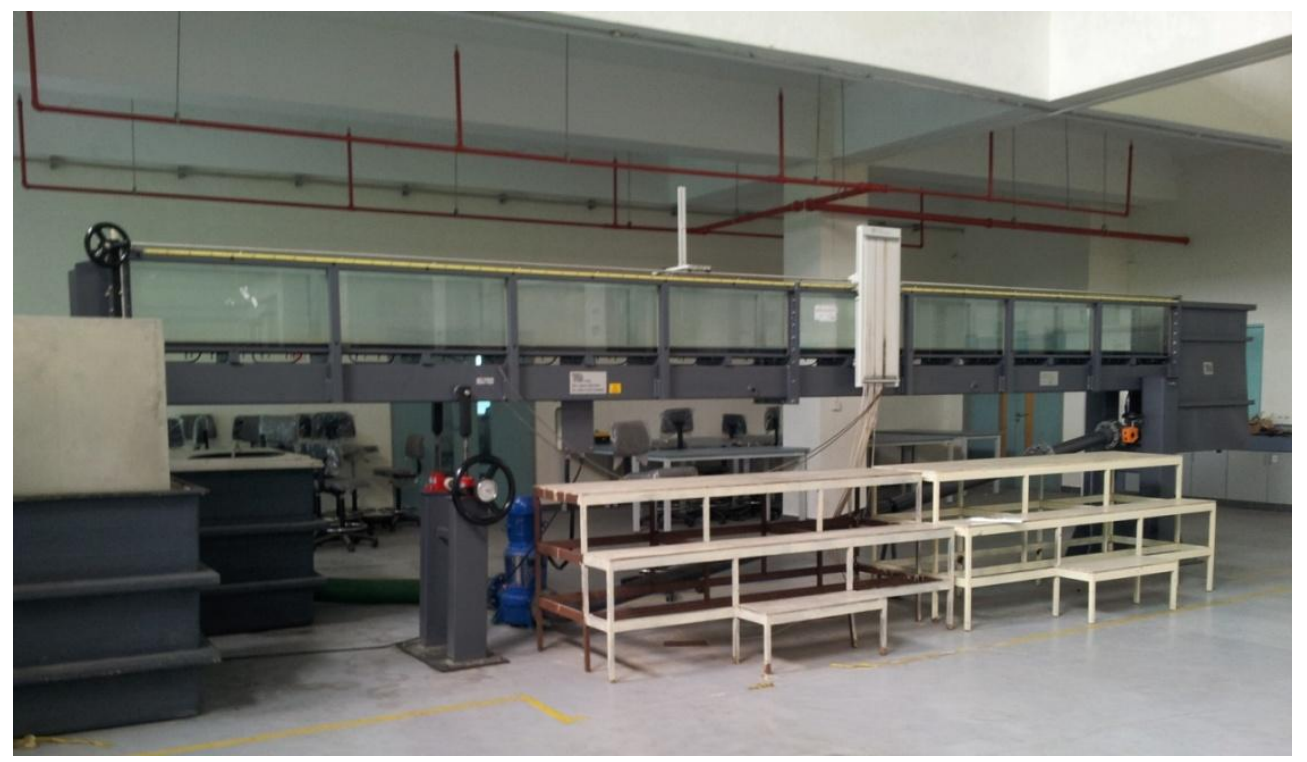

Figure 1: Flow channel in (UNIMAS) Hydraulics and Hydrology Civil Laboratory

\section{RESULTS AND DISCUSSION}

In this study, the head of water over the crest are determined from maximum flow to minimum flow with discharge ranges from $0.0014 \mathrm{~m}^{3} / \mathrm{s}$ to $0.015 \mathrm{~m}^{3} / \mathrm{s}$. The measured head are then used in weir equation derived from the Bernoulli's equation to determine the discharge. The discharge coefficient of weirs may depend on the shape, finishing of surface, degree of aeration, submergence ratio, and contraction, but most of the former studies mentioned that it depends mainly on the curvature of the streamlines, especially the vertical curvature. Regards with any types of weirs used and its working sections, it could be seen that the coefficient of discharge decreases as the head of water over the crest increases as shown in Graph 1 to Graph 3. The reason is that when the head of water over the crest increases, the flow is said thickens and fills out all the weir cross section. When the head keeps increasing, the crest will be submerged, causing the weir submergence and changing the discharge pattern. In these conditions, there is a great increment of the head for a small increase of flow discharge. The discharge now is not linearly increase with the head measurement. Thus, to balance the weir equation, the coefficient of discharge must decreases. In the study for rectangular weir, for flat level, the coefficient of discharge is 0.571503 while for 1:2400 slope, the coefficient of discharge is 0.52528 . Similarly, for the case of using vee notch weir, the coefficient of discharge is 0.5511375 for flat working section and 0.549017 for slope of 1:2400. It can be seen clearly that the $C_{d}$ for flat is higher as compared to slope. Based on the weir equation, when the head increases, the $C_{d}$ would decreases in 
order to balance the equation. Crump weir, however, the trend of the graphs is different. For Crump weir, the coefficient of discharge, $C_{d}$ is independent of the head and therefore the coefficient of discharge is constant when the head of water over the crest is lesser than $0.1 \mathrm{~m}$ and when the head of water over the crest is greater than $0.1 \mathrm{~m}$, the coefficient of discharge decreases. Overall, the results obtained shows that the coefficient of discharge decreases as the head of water over the crest increases. Theoretical and calculated coefficient of discharge of rectangular weir (Table 2), shows insignificance difference between $C_{d}$ determined by Kindsvater and Carter Formula. The differences may be due to study itself. The study by Kindsvater and Carter may be conducted many times with more data. Other experiments for vee notch weir show small difference between $\mathrm{C}_{\mathrm{d}}$ calculated by different formulas.

Table 2: Summary of coefficient of discharge using different formula

\begin{tabular}{r|rrrr}
\hline Weir Type & Rectangular & Rectangular & Vee Notch & Vee Notch \\
\hline Working section & Flat & Slope & Flat & Slope \\
Theoretical / Standard & 0.62 & 0.62 & 0.58 & 0.58 \\
Computed / Obtained & 0.571503 & 0.52528 & 0.5511375 & 0.549017 \\
Kindsvater \& Carter & 0.610948 & 0.610948 & - & - \\
Greve & - & - & 0.549545 & 0.549545 \\
Kindsvater Shen & - & - & 0.578 & 0.578 \\
\hline
\end{tabular}

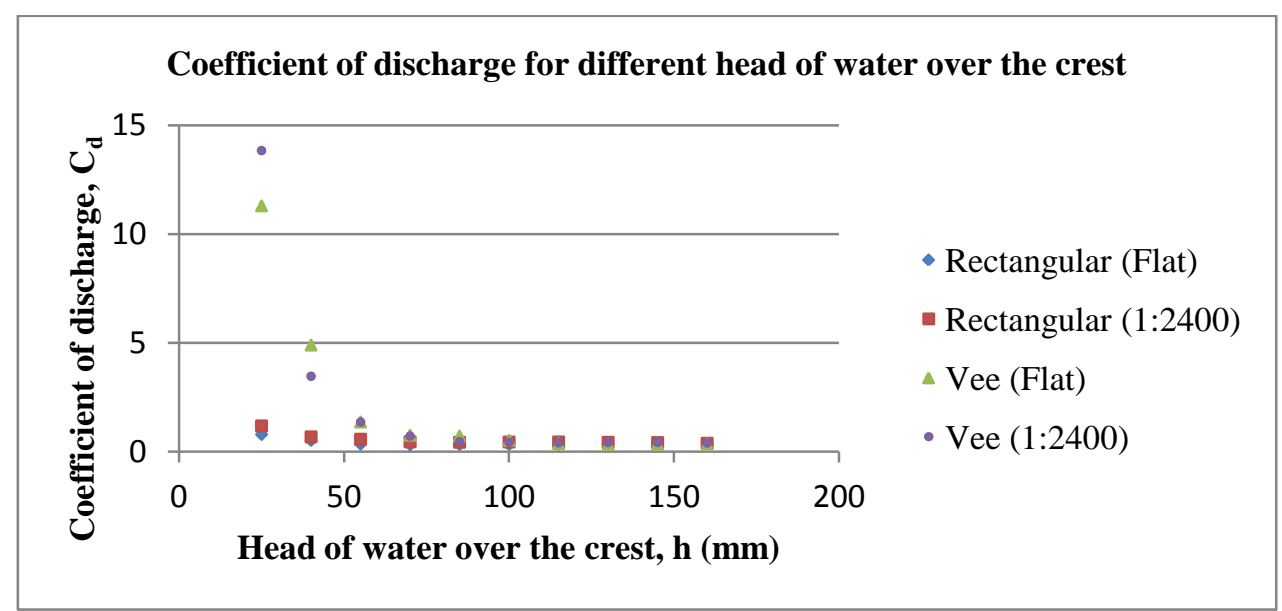

Graph 1: Coefficient of discharge and head of water over the crest for rectangular and vee notch weir (Flat and 1:2400)

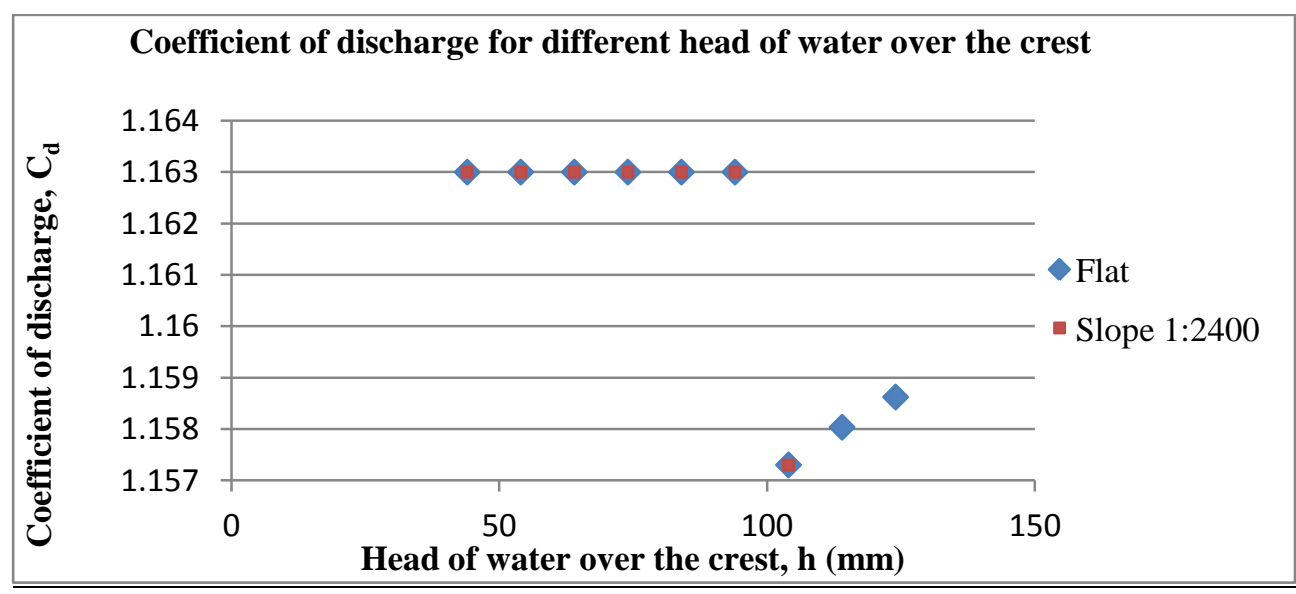

Graph 2: Coefficient of discharge and head of water over the crest for crump weir (undrowned for flat and 1:2400) 
UNIMAS e-Journal of Civil Engineering

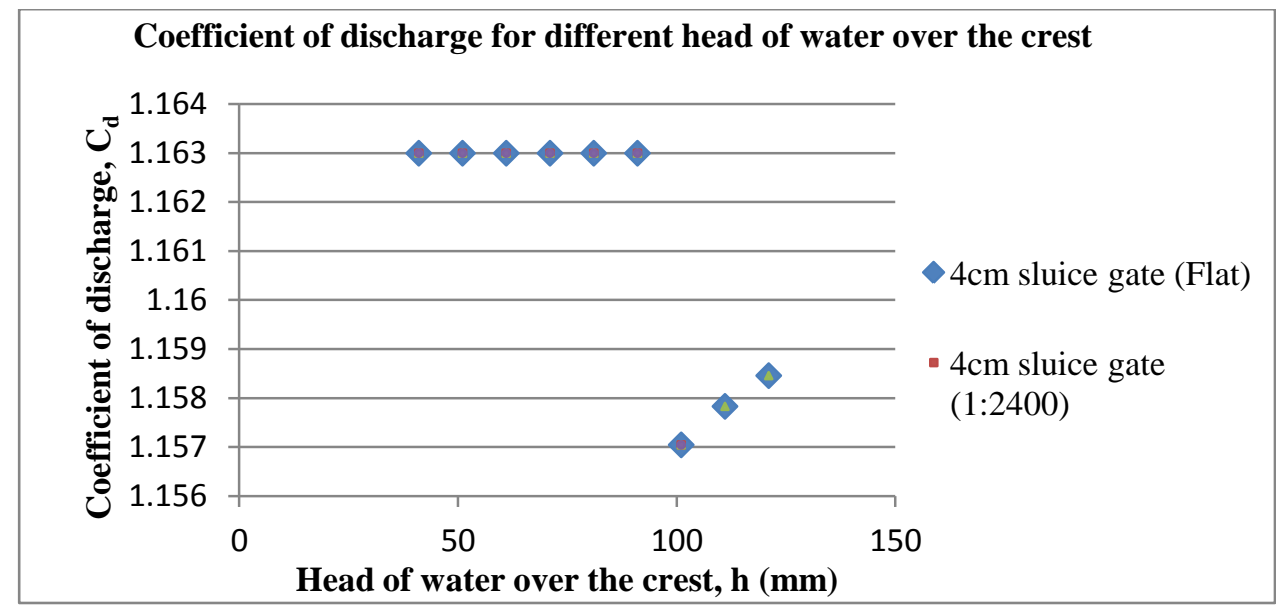

Graph 3: Coefficient of discharge and head of water over the crest for crump weir (drowned: $4 \mathrm{~cm}$ and $6 \mathrm{~cm}$ partially opened sluice gate for flat and 1:2400)

As for the study between head of water over the crest the discharges, overall, the discharge over the weir will also increase correspondingly as the head increases. Based on the weir equation, for rectangular weir and vee notch weir, the discharge of the weir is based upon of the coefficient of discharge. For crump weir, the discharge of weir is depends on the coefficient of discharge and also the coefficient of velocity. Graph 4 to Graph 6 shows the results for discharge computed versus the head of water over the crest.

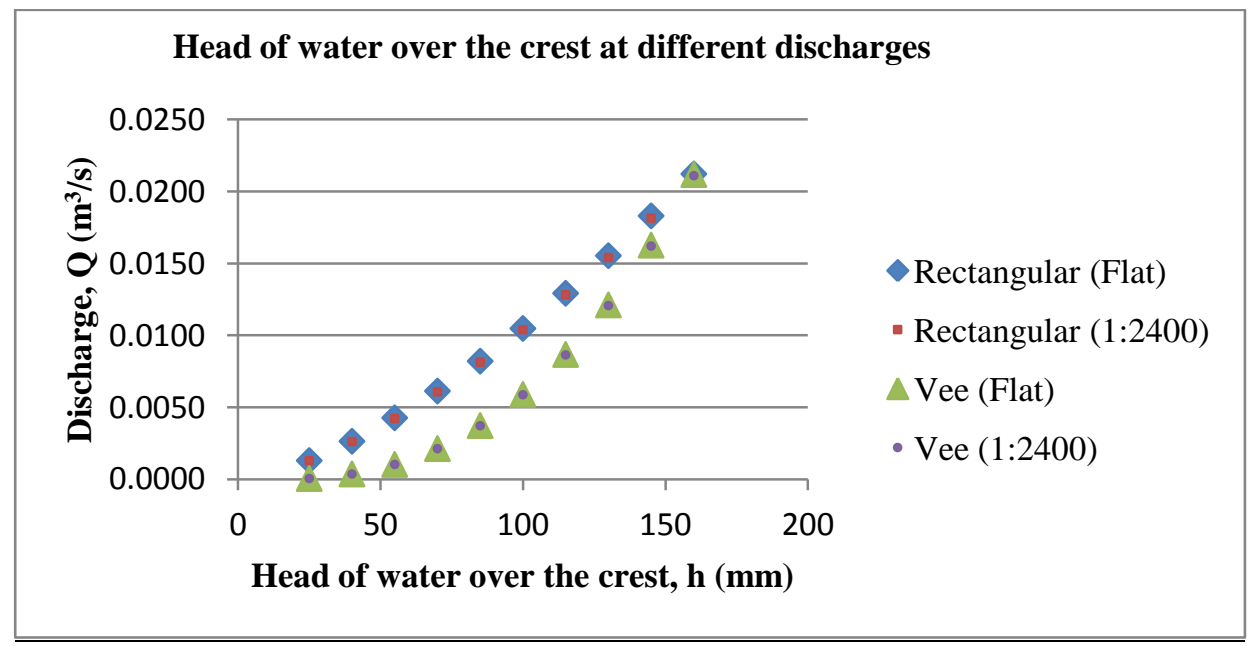

Graph 4: Head of water over the crest at different discharges for rectangular and vee notch weir (Flat and 1:2400)

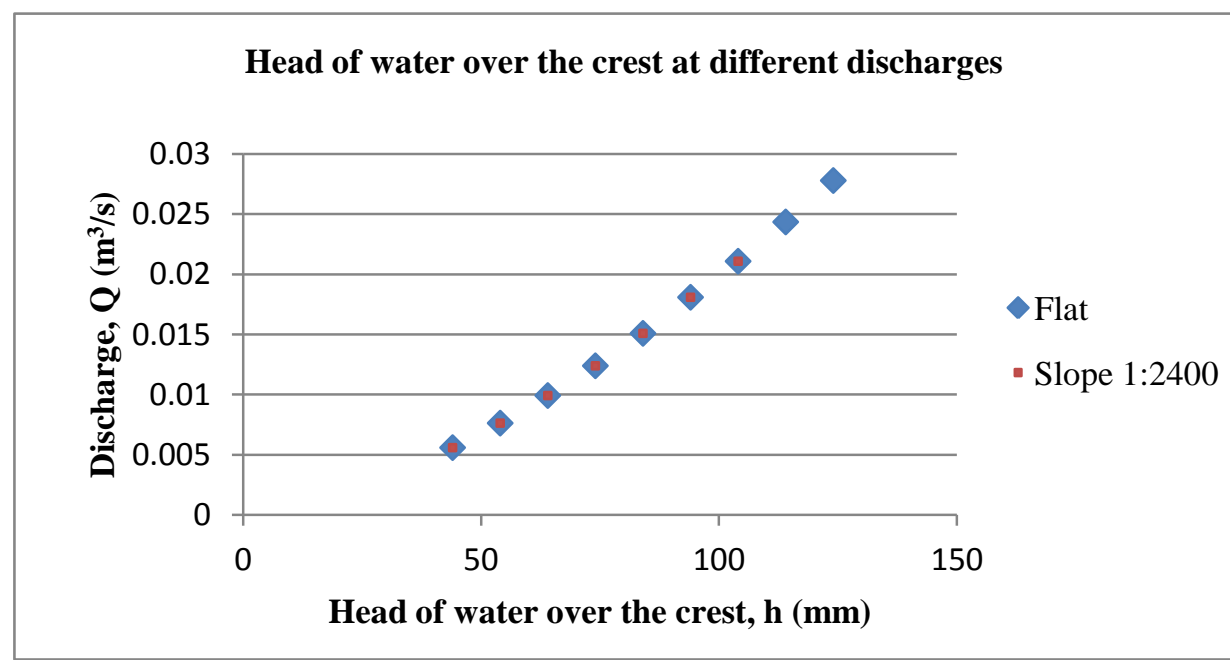

Graph 5: Head of water over the crest at different discharges for crump weir (undrowned: flat and 1:2400) 
UNIMAS e-Journal of Civil Engineering

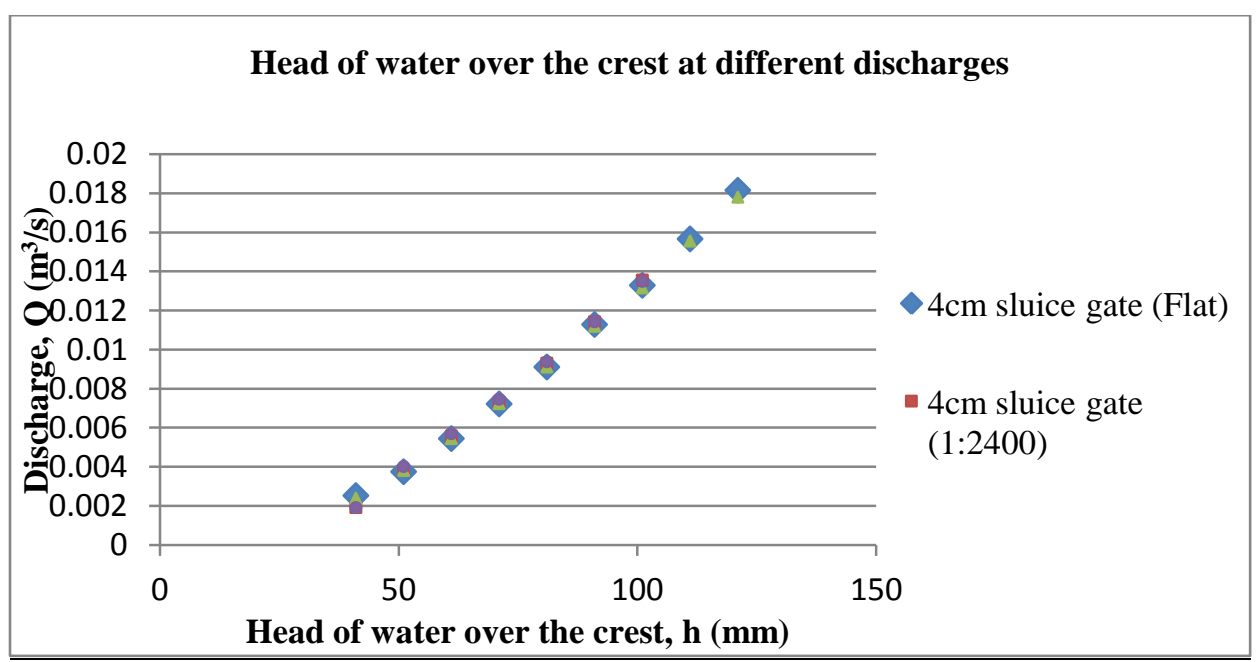

Graph 6: Head of water over the crest at different discharges for crump weir (drowned $4 \mathrm{~cm}$ and $6 \mathrm{~cm}$ partially opened sluice gate: flat and 1:2400)

In this study as well, the velocity of flow corresponding to different discharges is also determined. From Graph 7 to Graph 9, the velocity increases when the discharge increases. The velocities for 1:2400 slopes are higher as compared to flat. The reason is that due to sloping, the upstream water level is higher than the downstream water level in which the potential energy now is higher. When the potential energy is higher, kinetic energy would be higher as well. This can be justified using the Manning's equation. From Manning's equation, velocity increases as the slope increases. Therefore, by comparing flat and 1:2400, definitely the 1:2400 has higher velocity.

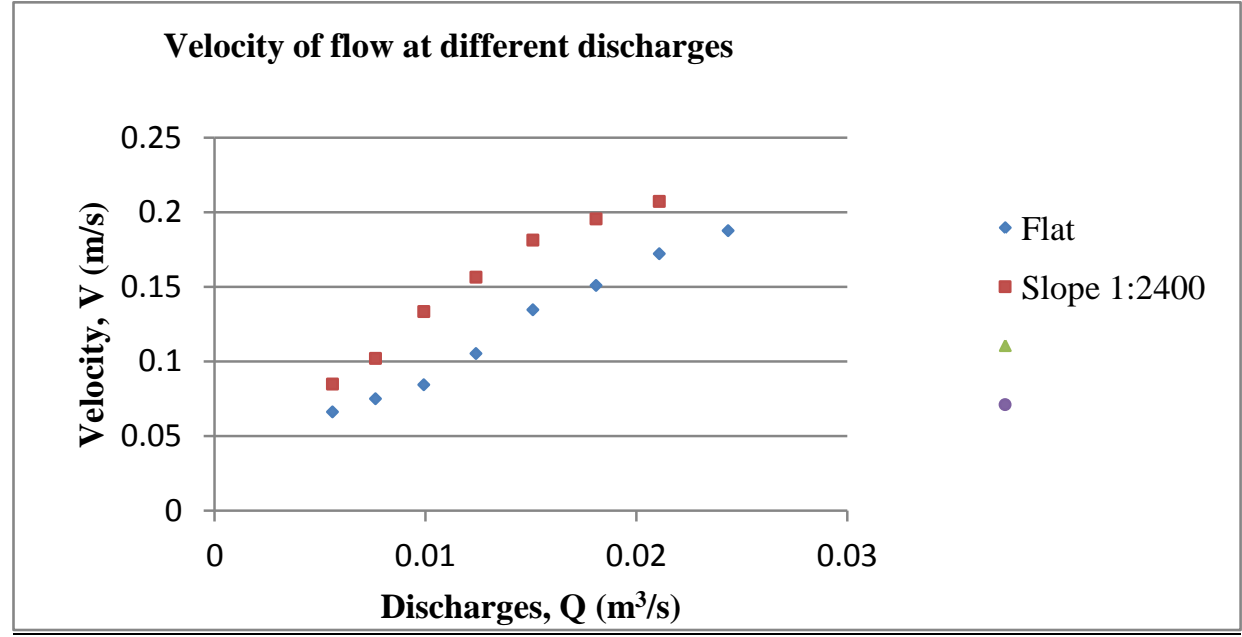

Graph 7: Velocity of flow at different discharges for rectangular and vee notch weir (flat and 1:2400)

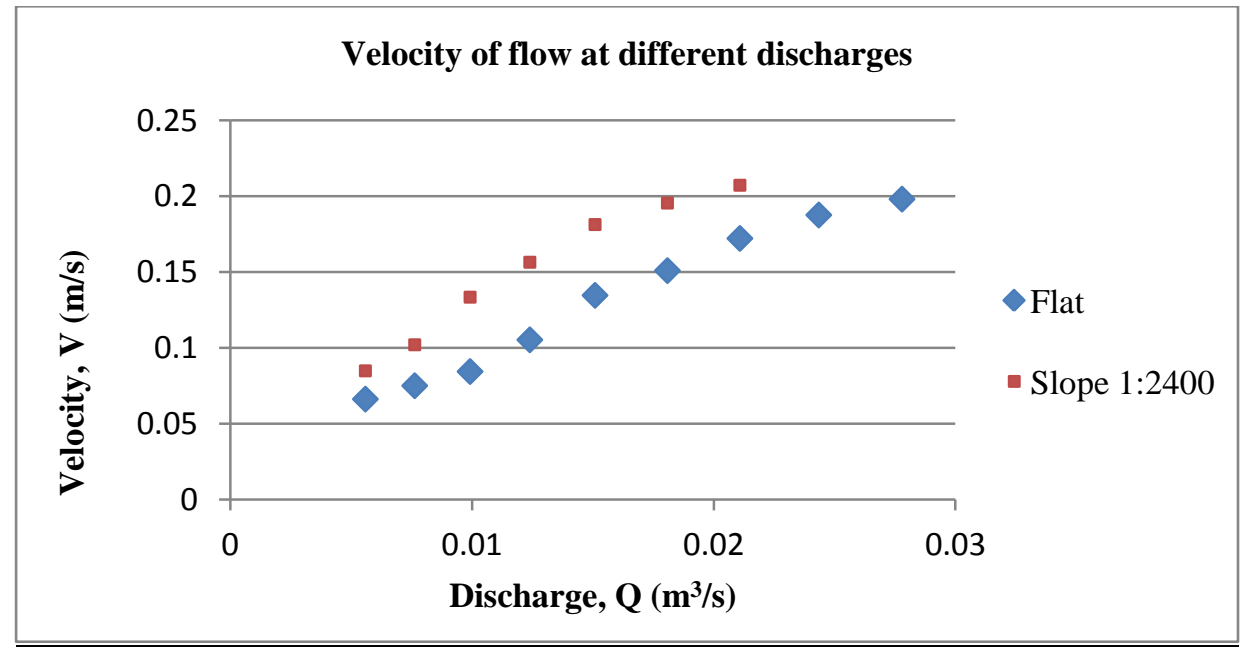

Graph 8: Velocity of flow at different discharges for Crump weir (undrowned: flat and 1:2400) 


\section{UNIMAS e-Journal of Civil Engineering}

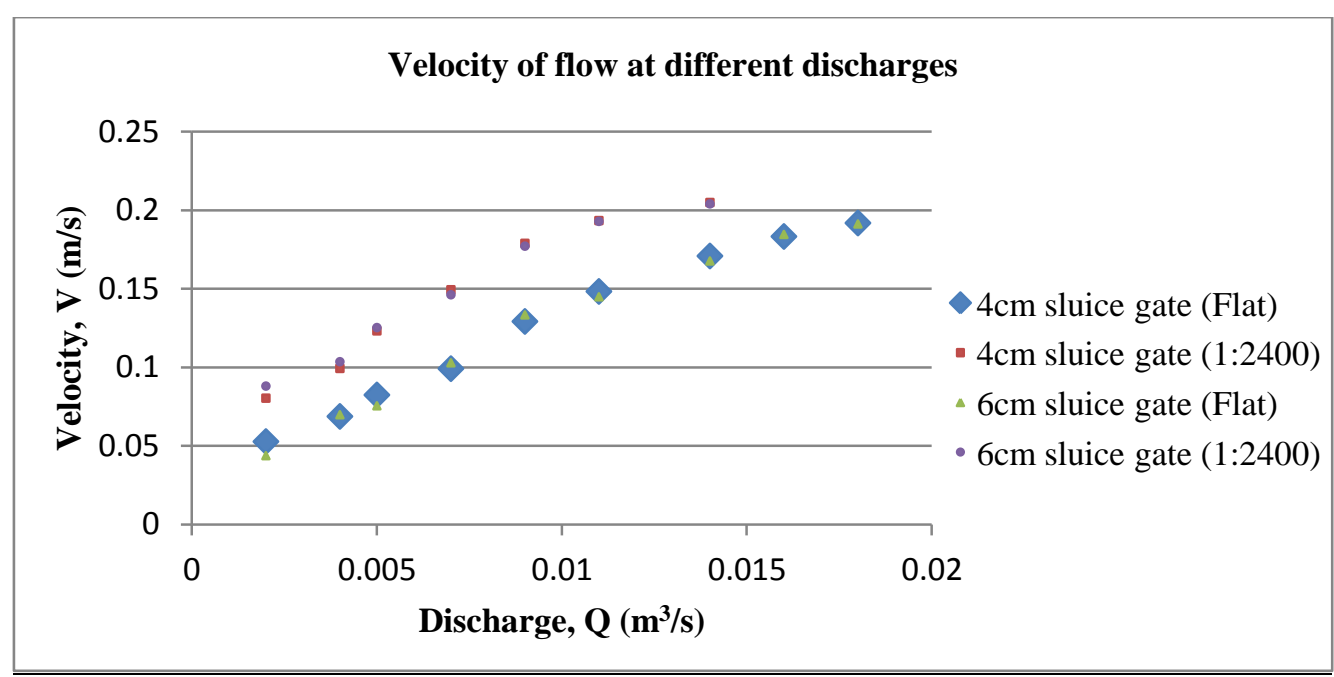

Graph 9: Velocity of flow at different discharges for Crump weir (drowned 4cm and 6cm partially opened sluice gate: flat and 1:2400)

\section{CONCLUSIONS AND RECOMMENDATIONS}

The results obtained show the effect of types on weirs on discharge. As the main objective is to determine the optimum discharge for different types of weirs, it can be concluded that the discharges of the weirs are based on the coefficient of discharge. This coefficient of discharge is related to other parameters as well especially the head of water over the crest. Different sizes of weir opening and different angle of notches are important factor to be considered as well as the geometry of the weir affects the head of water over the crest and the discharges, too. It can be concluded that these parameters are very important to be considered as from there, it can provide real value for detail design of using the design in irrigation and industries development.

Some recommendations for future study; conducting the study for different level of slope and analyze how upstream level at different slope influences the velocity as well as the discharges and conducting the study with different sizes of weir opening and different angle of notches to see how the geometry of the weir affects the head of water over the crest and the discharges.

\section{ACKNOWLEDGMENT}

We would like to thank the Department of Civil Engineering, Faculty of Engineering UNIMAS, Sarawak for their continuous support and kindness; as well as the Department of Irrigation and Drainage Sarawak for providing the required hydrology data as well as technical knowledge.

\section{REFERENCES}

[1] Rady, R. M.-H. “2D-3D Modeling of Flow Over Sharp-Crested Weirs”. Journal of Applied Science Research, 2011, pp. 2495-2505.

[2] Chadwick, A., \& Morfett, J. "Hydraulics in Civil and Environmental Engineering," New York: London; New York: E \& FN Spon, 1993, pp.397-411.

[3] Peakall, J. "Surface Tension in Small Hydraulic River Model - the Significance of the Weber Number," Journal of Hydrology, 1996, pp.199-212.

[4] Chadwick, A., \& Morfett, J. "Hydraulics in Civil Engineering," London; Allen and Unwin, 1986, p.492.

[5] El Alfy, K. S. "Effect of Vertical Curvature of Flow at Weir Crest on Discharge Coefficient," Ninth International Water Technology Conference. Egypt, 2005, pp.249-262. 